Article

\title{
Developing Connective Pedagogy in Cultural Research-A Case Study from the Teachers' Perspective in Adopting a Problem-Based Approach in Higher Education
}

\author{
Kaisu Kumpulainen ${ }^{1, *} \mathbb{0}$, Sanna-Mari Vierimaa ${ }^{2}$ and Eerika Koskinen-Koivisto ${ }^{3}$ \\ 1 Faculty of Social Sciences and Philosophy, University of Jyväskylä, P.O. box 35, 30014 Jyväskylä, Finland \\ 2 Faculty of Humanities and Social Sciences, University of Jyväskylä, P.O. box 35, 40014 Jyväskylä, Finland; \\ sanna.vierimaa@jyu.fi \\ 3 Department of History and Ethnology, University of Jyväskylä, P.O. box 35, 40014 Jyväskylä, Finland; \\ eerika.koskinen-koivisto@jyu.fi \\ * Correspondence: kaisu.kumpulainen@jyu.fi
}

Received: 1 June 2019; Accepted: 26 September 2019; Published: 4 October 2019

\begin{abstract}
The article examines the challenges university teachers face when adopting connective pedagogy in organizing teaching. Instead of studying the learning outcomes of the method, we decided in this research to focus on the teachers' experiences when doing things differently in a fairly traditional pedagogical institution like a university. In spring 2019, as a part of our new degree programme entitled Culture, Communities, and Change (KUMU) at the University of Jyväskylä, we implemented a multisensory ethnography course in collaboration with a third sector development project promoting village tourism in Central Finland. On the course, we applied a problem-based approach to implement the connective pedagogy through which we wanted to increase the students' working life skills and public engagement. While the main objective of the multisensory ethnography course was to develop village tourism and teach the students how to do ethnographic research, we also scrutinized our own teaching experience in developing higher education pedagogy through documenting our own activities in field diaries and analysing our own roles through self-reflexive ethnographic practice. The group discussions and the diaries of the teachers during the course are the data that has been analysed by means of social practice theory. The three elements of social practices-material, competence, and meaning-helped us to identify the important factors that should be taken into consideration when trying to change everyday practices in our work, in this case to organize collaborative teaching with a third sector development project. According to our results, a problem-based approach is an effective tool on a collaborative project course between the university and a third sector organization because it enabled us to practice connective pedagogy at a very practical level. There are also challenges in applying a new method. Studying our diaries and notes of group discussions and reflecting our experiences, we identified the following critical stages and weak spots: Planning and co-ordinating the course took a lot of time and resources and teachers must tolerate a certain amount of uncertainty. The competence of the teachers was also challenged; they needed to be open, for example, to dealing with unfamiliar research topics. Even if the teachers' meanings, motivation, and values were in accordance with the principles of connective pedagogy, there are still many contradictions in the meaning element of problem-based teaching practice. Above all, the teachers were compelled to question their role as experts when taking third sector actors as equal partners in producing new knowledge.
\end{abstract}

Keywords: problem-based approach; social practice theory; connective pedagogy; higher education; teachers' perspective; social practice theory; collaborative teaching; third-sector; ethnography 


\section{Introduction}

Novel ways to develop university teaching have attracted much attention due to changes in working life and expertise [1-4] yet the new practices have not been adopted as extensively as might have been expected [3]. One reason for the slow change in university pedagogy is the long traditions in the scientific field. University teaching has been based on and closely related to the long traditions of teaching scientific thinking. The teachers are above all scientific experts whose professional identity is rarely based on their passion to teach but rather on producing new knowledge [3]. Unfortunately, this is also reflected in the evaluation of universities' efficiency. Numbers of degrees and scientific articles produced now serve as more important indicators of teaching quality than students' learning outcomes. According to Tynjälä et al. [4], the relationship between higher education and working life should be studied from different angles: learning, educational institutions, working life, and society. Our study explores the view of educational institutions by revealing the perspective of university staff to analyse the experiences of individual teachers when adopting a new teaching method. The teachers' role is significant, and they are also often the reason why some innovations do not materialize in the everyday practices of university teaching. This does not mean only simple resistance to change but also different kinds of structural, social, and personal challenges that teachers face when trying to develop their teaching methods.

Changes in university pedagogy can be studied from the very practical level, from the everyday work in which the university staff plan and organize the courses. In this research, and as university teachers, we wanted to study our own experiences while adopting a connective pedagogical and problem-based approach to organizing a university course. We think that most of the teaching staff in higher education institutions face the same challenges and frustration as we do. We have studied different pedagogical approaches and theories, and we have a lot of ideas as to how we should develop our teaching. Yet, for many reasons, great ideas do not materialize as concrete everyday practices, due, for example, to lack of time, bureaucratic obstacles, and the demanding academic world [3]. By analysing our own experiences, we seek to find some answers to the questions as to why pedagogical reforms may be challenging from the teachers' point of view and what kind of support should be available when promoting new pedagogical innovations at the policy level.

We are particularly interested in studying the processes occurring when teachers put new pedagogical tools into practice. What kinds of challenges do teachers face when adopting a connective pedagogical method using problem-based learning to organize courses? What kinds of factors should be taken into account when planning a new kind of pedagogy in general? We study the process of implementing the idea of Connective Curriculum with problem-based learning through the framework of social practice theory [5]. The three elements of social practices-material, competence, and meaninghelp us to identify the important factors that should be taken into consideration when organizing collaborative teaching with third sector development projects. The following questions guided our reflections: How do university structures enable implementing the new kinds of novel teaching methods and approaches among different actors and stakeholders? What kinds of competences are required of the teachers? How do teachers process their ideas, aspirations, identities, and values throughout the course while working together with the third sector activists? We analyze these questions in the light of teachers' experience and joint reflections during and after a pilot course we taught in spring 2019.

In this article, we combined connective pedagogy, problem-based pedagogy, ethnographic observation, reflection, and social practice theory. Each of these has a different role in the organization of this article. Connective pedagogy and problem-based pedagogy created the teaching philosophy, which guided us in planning the multisensory ethnography course with the third sector partner. We formed a community of practice which used a problem-solving learning technique to answer the questions the Village Association presented to us. Ethnography was used as a method of both critical self-reflection and collaboration with the third sector in collecting and analyzing materials and different 
kinds of data. Finally, social practice theory [5] served as the main framework for the analysis. We also reflected how the new teaching philosophy functions according to the social practice theory.

The article begins by describing our new teaching philosophy, which combines connective pedagogy and problem-based pedagogy. It establishes a framework which teachers need to be able to operate and to which they need to adapt. Then, we move on to present the social practice theory, which sets the frame for the analysis. Next, we present the method and ethical considerations, and then discuss the results starting with the material element, followed by the teachers' competence element and finally the meaning element. The paper concludes with a discussion touching on the possible limitations and opportunities in adapting connective pedagogy in the university environment.

\section{Our Teaching Philosophy in Course Planning}

The multisensory ethnography course was developed using Dilly Fung's [6] idea of Connected Curriculum and the basic principles of problem-based learning (PBL). In this section, we first explain the dimensions of the Connected Curriculum framework, linking it to the communities of practice, and then move on to discuss the relevance of the PBL on this course.

Earlier research on connective pedagogy, at least in the British context, has focused on developing connections between the university and various organizations, associations, or businesses. Connective pedagogy has been used to study the skills acquired in the work-based context $[4,7,8]$. It has also inspired the development of community-engaged research methodology [9]. Moreover, connective pedagogy has been used to further develop other theoretical approaches such as integrative pedagogy [10,11], and it has also been used in inclusive education [12]. Our interest in connective pedagogy lies in curriculum development $[6,13]$ and in developing university-community connections [14-17]. The Connected Curriculum framework was used in the large research-intensive University College London (UCL) to improve the relationship between teaching, research, and communities. The most salient point is to highlight the need for connectivity, which is shown on six different dimensions linking personal, societal and institutional levels. In this multisensory ethnography course, we exemplified four of Fung's Connected Curriculum dimensions combining ideas of problem-based learning. Next, we open up these dimensions.

Fung's [6] second dimension "research activity is built into each programme" includes a sequence of learning activities that empower students to apply their skills and dispositions in doing research. Carnell and Fung [13] assert that it "provides a structure for gradually building research skills that are vital for both academic study and professional life". The third dimension "students make connections across subjects and out to the world" focuses on the importance of students making connections between their own subjects and other disciplines. Fung also emphasizes that students should engage with international perspectives and develop an awareness of knowledge traditions from cultures that differ from their own. It helps students to articulate their own values and reflect their contributions to society. The fourth dimension "students connect academic learning with workplace learning" states that the programme of study should equip students for professional work and for lifelong learning. Professional expertise has become more complex, and students should learn more about how to integrate theory and practice more effectively $[10,18]$.

Finally, the fifth dimension "students learn to produce outputs-assessments directed at an audience "explains the importance of working together in partnership with local communities [6]. Wenger's [14] article on social learning systems and communities of practice shows what kinds of learning opportunities and challenges working with community partners entail. He defines a social learning system in terms of social competence, personal experience, and the modes of belonging. Communities of practice are "the basic building blocks of a social learning system because they are the social 'containers' of the competences that make up such a system" [14]. Competence established by our communities over time is formed of three elements. First, members have collectively developed an understanding and set the boundaries of their community, forming a sense of common enterprise. Members' competence emerges from understanding the idea of enterprise so well that 
they can contribute and be accountable to it. Wenger's second point emphasizes mutual engagement. Members establish shared norms for their interaction, leading to the third point, shared repertoire of communal resources. This includes language, routines, sensibilities, artefacts, tools, stories, etc., which a competent member is able to use appropriately.

Wenger [14] argues that competence is in interplay with our experience (in the context of a given community and beyond) and that it is in this interplay that learning takes place. However, competence and experience may stand in various relations to each other. Wenger illustrates this at the boundaries of communities of practice. He takes the view that, at the boundaries, competence and experience need to converge and also to diverge to some degree so as to afford learning opportunities. This means that learning may not occur if competence and experience are too congruent. On the other hand, the same happens if competence and experience are too disconnected. Hence, Wenger argues that experience and competence need to be in close tension so that learning can be maximized. This occurs at its best if there is some intersection of interest or activity. Members should also openly discuss differences and similarities and retain a non-judgmental attitude.

On the multisensory ethnography course, the teachers, students, and third sector partners formed a community of practice. This required teachers to be a part of the problem-solving teams as equal partners with students and third sector partners. Problem-based learning represented an instructional method in this study because the tasks of the multisensory course were decisively influenced by the objectives of the tourism project. PBL can be seen as the umbrella concept for various approaches, as problem-solving learning, problem-based learning, and problem-oriented project learning $[2,19]$. All these can be used in connective pedagogy, and in all of them, students resolve real-life problems or tasks in groups. Problem-solving learning is the most technical approach, where the students are expected to find the "right" solutions to the problem posed by the teachers. Problem-oriented project learning is the most dialectic approach, where students also have to construct the problems to be solved. Problem-based learning is located somewhere between these two methods. The problem may be posed by the teachers, but there are no predetermined answers to which the process should lead.

PBL has long historical roots. Hmelo-Silver [20] even connects it to Kilpatrick and Dewey, who emphasize practical experience in learning. Savin-Baden and Major [21] use Boud's [22] flexible and fluid notion of PBL, meaning that it varies according to the discipline and the goals of the programme. Students learn to solve problems in collaborative groups engaging in self-directed learning [20]. Collaboration skills are essential in connective pedagogy, making the PBL method an appropriate way to assist students to learn these effectively.

Savin-Baden and Major [21] have identified the following characteristics that are common to courses organized according the principles of problem-based learning:

- $\quad$ acknowledgement of the learners' experiential base;

- emphasis on students taking responsibility for their own learning;

- crossing of boundaries between disciplines;

- intertwining of theory and practice;

- focus on the processes rather than the products of knowledge acquisition;

- change in the tutor's role from that of instructor to that of facilitator;

- change in focus from tutor's assessment of outcomes of learning to student self-assessment and peer assessment;

- focus on communication and interpersonal skills so that students understand that in order to relate their knowledge, they require skills to communicate with others, skills that go beyond their area of technical expertise.

Connective pedagogy emphasizes the role of other communities or co-operation partners, which makes it challenging to apply problem-oriented project learning or to any other method based on the students' role in constructing the tasks of the process. In the fifth dimension of connected curriculum, Fung [6] discusses how students should learn to produce outputs directed at audiences. 
On our project, audiences refers to the people possibly benefitting from their assessments, namely village associations and local entrepreneurs. It also implies the existence of a fourth "invisible partner", whose perspective should be taken into account. This makes connective pedagogy a complicated and challenging process.

\section{Transforming the Teaching-The Social Practice Perspective}

In this article, we do not focus on the learning outcomes of the connective pedagogy and problem-based approach but on the teachers' point of view in adopting these new teaching methods by applying the ethnographic practice of critical self-reflection. Focusing on the teachers' experience in practising connective pedagogy emphasizes the importance of the social dimension. Studies on the social dimension of teaching have focused on the learning outcomes and experiences [23], but there is no research concentrating on teaching as a social practice from the teachers' perspective. According to Mälkki \& Lindblom-Ylänne [24], reflection is seen as an important part of teachers' competence and the developing process of pedagogy in higher education, but reflection skills do not guarantee change at a practical level. They highlight the importance of identifying the factors that prevent or enhance the expected changes in teaching practices.

We define teaching as a social practice, which entails focusing on the practicalities, activities, and interconnections of routine of teachers' work. In order to study our own activities and choices as teachers, we apply social practice theory [6], which has been applied, for example, in studying technology [25], agri-environmental practices [26-28], climate change [29], and food systems [26,30]. Since the classical social practice theories of Anthony Giddens [31] and Pierre Bourdieu [32], the approach has been refined in several studies $[33,34]$. In this article, we have chosen a very practical way to apply social practice theory, using it as the frame to analyze everyday life of our teaching experience. In social practice theory, researchers are interested in the dynamics of change. Social practices can be divided into the following three elements: materials, competences, and meanings [5]. The material element refers to physical things, objects, and technologies, and the competence element refers to individuals' skills and know-how and meanings to ideas, aspirations, identity, and values. The three elements of social practices are comparatively stable, but the ways in which they connect and reconnect with each other form the dynamic of change and transformation [5].

Social practices usually change slowly [5], which also explains why new pedagogical approaches or philosophies do not necessarily reflect the practical everyday life of teaching. Social practice theory is interested in understanding the dynamics of change [5]. Why do some practices disappear and some of them become a normalized and stable way to act in our culture and society? It is quite easy to build new innovations, for example in developing teaching, but to maintain them to become a permanent part of everyday life is more challenging. Especially if there are contradictions between the new pedagogy and the existing practices, the change may be difficult, slow, or even impossible. Most often, teaching is a combination of elements from the existing practices and from innovations or trends, which means that change is slow. The less the new approaches contradict existing practices, the easier it is to adopt new ways to organize teaching. The adoption of any new practice, as a new teaching method, means that there will be changes in the connections between the three different elements.

The material element [5] consists of financial and time resources, places or rooms in which to organize teaching, and the structural or policy frame affecting the everyday teaching in the university environment. When a teacher or teachers decide to organize courses in a different way, they must take the material conditions into consideration. For example, do they have enough material resources to be able to carry out their plans? Are there suitable partners available to find interesting and relevant problems for students to solve? Are there financial resources for fieldwork? Are the teaching programmes and working schedules flexible enough to take account of partners' timetables and expectations? The university policy directly affects the resources available, but also indirectly affects what kind of activities are rewarded, for example, in staff recruitment. 
The competence element [5] is especially significant in problem-based learning because the teachers are not able to plan the course solely around their own scientific expertise. The projects are often constructed according to the partners' aims and not only the universities' learning objectives. The teachers' role is to negotiate an entity in which the interests of the different parties converge and to instruct the students' group work. The role of facilitator means that the social and communicative skills are in a more important role than in traditional lecturer-led teaching, which challenges the teachers to re-evaluate their own role in the process [20]. The reflective skills are seen as an important part of teachers' competence in higher education, but it is not self-evident that these transform into the everyday practice of university teaching [24]. There may, for example, be material elements that prevent the competence element from influencing how social practices are shaped.

The meaning element [5] of teaching consists of teachers' values and aspirations regarding what they deem important in teaching and learning. What is their pedagogical philosophy? How do they perceive themselves as teachers, or how do they perceive the students' role in the learning process? The meaning element is the core of the motivation and the commitment to change our behaviour and adopt new practices in our everyday work. When planning any changes, the pedagogical innovations should be according to the teachers' own evaluations of how they consider the courses should be organized. Even if there were material resources available to practise problem-based teaching and if the staff members have the required competences, the learning outcomes would probably remain low if the teachers do not understand why the course is organized differently from what they are used to. On the other hand, even a strong motivation is not enough if the necessary competence is lacking. This may be the case, for example, with many digital innovations and learning environments.

Studying change in teaching practices means that we are doing research on our own learning process. According to Wenger [14], social learning consists of social competence, personal experience, and belonging, which can be located to the second and the third elements of social practice theory. However, we also want to study the context and the structures in which the teaching takes place, the material element of the teaching practices, to be able to draw comprehensive conclusions about the process of adopting connective pedagogy in practice.

There are also contradictions between social learning and social practice theories. According to social learning theory [14], there should be some tension between competence and experience to be able to maximize learning outcomes. Yet, according to social practice theory [5], if we are interested in making the new practices a sustainable part of everyday work, there are risks with any tensions involved. To be able to increase the role of connective pedagogy in university teaching, there should not be contradictions between the material, competence, and meaning elements of everyday teaching. Changes inside the elements are needed, but they must not be too dramatic to jeopardize the links between them.

\section{Methodology and Ethical Considerations}

In studying the practices of our teaching and our own learning process, we apply ethnographic methodology. Social practice theory emphasizes the materiality of everyday life [35], which is also central to the ethnographic approach. Ethnography is the study of social interactions, behaviours and perceptions occurring within groups, teams, organisations, and communities [36]. Ethnographic fieldwork consists of participant observation, during which the ethnographer takes an active part in the daily activities she observes [37]. The aspect of participation affords ethnographers opportunities to gather empirical insights into social practices. Ethnography is also a reflexive methodology where the role of the researcher as embodied subject is crucial. It offers versions of ethnographers' experiences of reality that are as faithful as possible to the context, negotiations, and intersubjectivities through which the knowledge is produced. Thus, it is an effective tool for assessing roles and rendering visible the complexity of social reality. In ethnographic research, the researcher herself is the most important research tool: in addition to observing others, the researcher also conducts participant observation and autoethnography, studying her own perceptions and subjective experiences [37,38]. As ethnographers, 
we were not only interested in the meanings we attach to our work but in the social interactions and social context of our reality.

During our course, our students applied the method of sensory ethnography, which emphasizes sensory and embodied experiences as a way of knowing about the world [39]. At the core of sensory ethnography are sensory experiences (sight, hearing, taste, smell, and touch) and their role in social practices and relations [39]. The idea is that, through studying their own and other people's sensory experiences, ethnographers access relevant nonverbal and seemingly meaningless and self-evident information that affects our everyday life and daily practices $[40,41]$. We chose the multisensory approach because we wanted our students to acquire skills of reflection and to encourage them to experience personally — not merely observe-the activities of adventure tourism that our collaborative partner, the village association, was developing. We also anticipated that the multisensory approach would engage the students to personally involve themselves in the life in the villages and to experience the way of life that the tourist activities were seeking to showcase and marketize.

Learning by doing and reflexive practice are crucial for both the ethnographic method and problem-based learning. The main assignment of our students on the sensory ethnography course was as follows: based on their fieldwork experience and analysing the sensory ethnographic data, the students were asked to produce marketing material for the villages in the form of posters that highlighted the most profound and unique experiences of the test days. Fieldwork consisted of participating in the tourist activities, photographing and videotaping them, interviewing other students in situ about their experiences, making notes on their own experiences, and keeping field diaries about the fieldwork experience immediately after it ended.

We as teachers also participated as ethnographers in the fieldwork experience, which in our case meant fully experiencing the activities of the test days as part of the test group. We, however, had a double role as instructors of groupwork and ethnographic documenting and as test clients, just like our students, who had not previously visited the destinations or received any prior information about the contents of the test days and various activities they involved. We also kept field notes and wrote diaries of our experiences immediately after the test days ended, sharing the texts with the rest of the group in the online learning environment on the online platform Microsoft Teams. We used another online platform, Moodle, to distribute and store materials for students.

In addition to participating in the fieldwork as ethnographers, we, the three teachers of the course, held short debriefing sessions after each class and after the fieldwork days. During our debriefing sessions, we scrutinized the dynamics of the groupwork that we had observed in the field, our own personal experiences of doing sensory ethnography, and the various roles that we simultaneously assumed in the field and in the classroom. The testing of tourist activities in the first village was done in two different groups. Two of us were in the same group and could therefore take turns between the two roles of teacher and ethnographer. We all noted that, due to the need to provide help with translating and giving a hand to the organizers of the activities, we were not able to become as engrossed in them as our students did. We also had somewhat different roles in relation to our collaborative partners. The teacher in overall charge of the course knew the collaborators and their project beforehand due to having a commission of trust in their organization.

On the course, we wrote diaries and made field notes from two perspectives. We applied sensory ethnography to develop tourist attractions with the students, but we also studied our pedagogical experience as teachers. In this article we have used only those parts of the data which deal with our experiences and observations of teaching and developing connective pedagogy. In addition to personal diaries (a total of 30 handwritten pages), we made notes on our group discussions (three while planning, three during, and one after the course). The data was analyzed by classifying the data according to the different elements of social practice theory (material, competence, and meaning elements) [5]. The detailed ethnographic field notes allowed a close analysis of experiences and observations.

The multisensory course included different levels of ethical questions. Some of them concerned the material produced for the village tourism project and for the research purposes, and some of 
them had to do with the development of teaching and the students' right to high quality education. When we began planning the course, the new ethical guidelines were just developing in Finland and in our university. Hence, it was challenging to create a suitable consent form and an assurance of confidentiality because the rules kept changing and reforming. As a result, we had created two lengthy documents and were concerned that the students might not want to read and sign them. If that had happened, it would have ruined the whole research project. Thus, we needed to take plenty of time at the beginning of the first lecture to explain their content and to complete them together. The students were already knowledgeable about the new process. To our surprise, all students wanted to participate in the study, although it was voluntary. The process was more difficult and stressful for the third sector staff, who still needed to find out how the new changes would affect them.

The students signed a consent and an assurance of confidentiality notice that allowed us to study the ethnographic research material (their interviews with each other, videos, and photos) they produced including their assignments and written reflections. During the research process, we stored the material in a locked cupboard at the university. All students also gave their consent to the material collected during the course being stored in the University of Jyväskylä's Open Science Center/Jyväskylä University Museum. The consent followed the ethical guidelines of the University of Jyväskylä on personal data management.

In addition to the ethical questions concerning research material, we had to reflect critically on the whole idea of developing teaching methods. One reason that motivated us to complete the study and write this article was to discuss the future role of connective pedagogy in our study programme. There were a lot of questions to consider. Why do we need a new pedagogical approach? Are we really doing this to improve the students' learning process? Are the objectives of the third sector partner in accordance with the students' learning objectives, or might they be displacing some other objectives relevant to the students? Are there some students, for example those with learning difficulties, who might be excluded from the course because of the new method? Connective pedagogy and problem-based approaches require a lot of social interaction and initiative on the part of the students, which makes it a challenging approach for some students. Because our course was optional, we did not have to plan alternative ways for students to complete the course, but these questions still need to be kept in mind when planning any new teaching experiments.

\section{Results}

In this section, we reflect on our experiences as teachers on the multisensory ethnography course. First, we report how we constructed the course according the principles of the problem-based approach. Second, we analyze the teaching process through the different elements of social practice theory. Third, we consider the methods we applied in studying our own learning process. Finally, we draw some conclusions on how the different elements of the teaching practice interact with each other.

In connective pedagogy, it is important to build connections between teaching, research, and communities [6]. On the multisensory ethnography course, this meant that the students did not only apply the ethnographic research method but had to think one step further, about how their research could help rural communities to develop their tourist attractions. The easiest task in this process was to write down the principles aspired to in building the course, but how can these ideas be put into practice? How can teaching, research, and community development be connected in one course? This was the big question when we started planning our multisensory ethnography course and why we wanted to study our own experiences during the process. We did not want our ambitious tasks to be mere words on paper.

The idea of the multisensory ethnography course came up in a discussion with the Village Action Association of Central Finland when they were writing their project plan on village tourism. The organization was interested in getting university students involved in their project, and we as teachers of cultural studies saw the project as an excellent opportunity for our students to be able to participate in a development project, and to improve their methodological skills at the same time. 
We considered it important that the students should learn how to collect data, analyze it, and make use of their research results as a part of a real-life development work. The course objective was to help two local village action associations to develop tourist attractions with the help of ethnographic research. The multisensory ethnography course comprised theoretical and methodological lectures and fieldwork. The teachers of the course were also immersed in the research process, which put them in a new position equal to students.

The course was targeted at our own ethnology students and exchange students from various university departments, which meant that there was some variation in the students' background knowledge of ethnographic methods. The students' disparate backgrounds increased the multidisciplinary aspect of the course, offering an opportunity to reflect the fieldwork experiences through the various cultural contexts. For example, people from Asia, Germany, or from Finland might attach different meanings to their experiences or appreciate different things. The mixture of international and Finnish students was very fruitful because the village tourism project wanted to learn how to marketize the attractions for international tourists. First, we had two lecture days teaching the students the multisensory ethnographic method and data collection. After the introductory lectures, we had two fieldwork days in the villages of Koivisto and Tikkala, where local people had planned different kinds of activities and adventures for us. The students collected data by recording, making notes, and taking photographs. The third phase of the course consisted of lectures about textual and visual analysis, rural tourism, and applied ethnography.

At the end of the course, we held a one-day seminar where the students presented the results of their study. They were instructed to introduce the highlights of the activities during the two fieldwork days and to analyze their multisensory elements-what kinds of cultural experiences were offered. Another task of the presentations was to reflect on how the activities in the villages had succeeded, who would be the target recipients for the activities, and how the villages could develop the adventures further. The students also created two posters introducing an activity or activities of each village as a tourist product. The aim was to visualize an advertisement of the adventure tourism for both villages.

In the multisensory ethnography method, the emphasis is on human experiences and interpretation, especially on the subjective sensory experience. In studying the villages' tourist attractions, the students' task was to perceive their own experiences. They and their teachers assumed three simultaneous roles, namely as learners, researchers, and tourists. The students had to take more responsibility for their own learning in groupwork than on a course led by a teacher. The assignments were not detailed, nor were there any right answers. This may be confusing for the student, but it also gives more space for their own insights and discoveries. The course was multidisciplinary, combining cultural and tourism research. None of us teachers were familiar with tourism research or development, which moreover made the course a great opportunity to think about cultural and ethnographic studies from a new perspective.

The essential idea of the course was to combine theory and practice. We saw the great potential of the multisensory ethnography in studying human experience and wanted to learn how to make use of it in development work, in this case in rural tourism development. It was also exciting for the students to have an opportunity to participate and exert influence in a real-life problem, in this case how to develop village attractions and activities for international tourists. On the course, the focus was on the learning process and on posing good questions when analyzing and developing village tourism. The ethnographic method is a subjective tool with which to do research emphasizing the role of ethics in reflecting and revealing the process of how the interpretations are constructed [37]. The combination of scientific and community development approaches may be contradictory and confusing, but we as teachers felt that it opened up more diverse perspectives on reality. During the lectures on discourse and visual analysis, we not only studied how to view the data critically, but we were also taught about how representations and visual material can send a certain message to the receiver. We had to think about the ethics of the process from diverse angles. The integration of theory and practice leads to critically reviewing the scientific theories and methods themselves. The process raised the question, 
which of the interpretations is more accurate, the one that we sense from our experience or the one that we read from the data we have collected?

Compared to traditional university teaching, problem-based pedagogy has a marked effect on the teachers' role. They must be able to adopt the role of a facilitator, which is not a matter of lecturing students and providing the right answers. Instead, teachers assist students to solve the problem by themselves [1]. The theories and methodologies were introduced to the students on the course as tools that help them to solve their task in groups. The assessment of the students' learning on the course was a difficult task. There were no theoretical essays or exams to evaluate. We asked the students to keep learning diaries where they could reflect what they had learned on the course and how multisensory ethnography works as a method in developing tourism. We also collected evaluation forms at the beginning and end of the course, which helped the students to analyze what kind of learning they had hoped for and what kind of learning they had achieved during the course. This is also very important information for us in developing our future pedagogical approach. The most important evaluation process on the course was the closing seminar, where the staff of the village organizations gave the students feedback on their presentations, posters, and ideas, and on how the villages concerned could develop their activities to attract foreign tourists.

The multisensory ethnography course was an optional course, which means that all the participating students were interested in the subject and were also willing to do groupwork. The students knew that they would have to be more sociable than on an ordinary university course. The course language was English, which was not the first language of any of the students, and thus inhibited communication. At the beginning of the course, we underlined that students' possible grammatical errors would not affect the evaluation of the course. We also wanted to encourage all the staff members of the village organization to speak English, even if they did not find it easy. If someone did not find the right English words, someone else helped to translate. This was also one way to increase the team spirit and build an atmosphere where everyone was able to help each other. There was also a lot of non-verbal communication on the course, which increased the team spirit and made up for deficiencies in language skills. During the fieldwork days, activities included communal action, baking or playing together, sawing a hole in the ice, and having a sauna together. The more the spirit of communion grew, the more blurred the roles of the different participants became.

We teachers felt during the course that we were a part of the community of practice [41], which had a shared goal to help the villages to develop their tourist attractions. At the beginning of the course, there were three groups of people-students, teachers, and project workers-but at the end, it was not so easy to perceive the different roles of the participants. It is important to remember when practicing connective pedagogy that the participants form a community of practice where everyone learns from the other members $[15,17]$. There was a lot of expertise in our community to be shared among all concerned. The project workers of Village Action Association of Central Finland were the experts on village development sharing their knowledge about the subject of the course. They were present at every meeting and lecture because they also wanted to learn about multisensory and applied ethnography. Their objective was to get some new perspectives for producing and advertising village attractions, but there were also unexpected learning outcomes. Before the beginning of the third lecture, one of the project workers told us how he had just started to read earlier research reports about the rural community of his neighbourhood. Despite not having studied at university or read any scientific publications, he was enthusiastic about discovering how many accounts there may be about one place written from different angles and approaches. Sitting with us in the lectures, he was encouraged to read scientific publications and began to understand the different approaches and contexts affecting how scientific study designs and results are presented and represented.

In the last session, at which the students presented their development ideas for the villages, the project workers were in the expert role. We teachers also had many new things to learn, especially about development work and tourism. Researchers and development workers both need 
to write many applications and reports, but the discourse is different. We learned a lot from the developers' point of view about how they needed to publicise their actions and strategies.

\subsection{The Material Element Sets the Frame for the Pedagogical Development Work}

The material element of social practice [5] consists of different resources such as financial and time resources that are needed in organizing a course. University policy is also a part of the material settings of teaching. It affects the background and provides a structural frame for organizing teaching.

We started co-operation with the village organization when they were making the project plan to apply for funding, which enabled us to obtain financial resources for the course from the project budget. One of us belongs to the board of the Village Action Association of Central Finland, which enabled co-operation in the planning stage of the project. This was a relief because we did not have to be entirely dependent on the university's financial support, thereby enabling us to plan the fieldwork days according to our own preferences. During the two fieldwork days, we tested and analysed different kinds of village attractions with the students, for example, made smoked salmon, baked, tried facial aroma therapy, and participated in handcraft workshops. Sometimes, we even forgot that we were not on a class excursion but conducting scientific research. The university's own financial resources would never have allowed us to offer the students (and the teachers) such experiences. Hence, it is important to be already involved at the community partners' planning stage of development projects.

We also used guest lecturers on the course to introduce various analysis methods and to teach rural tourism. Because of the multidisciplinary nature of the course, we did not have all the expertise that was needed to complete the course tasks. This is often the case in problem-based courses, where the topics are formed according to the partners' tasks and needs. The university gave us some funding with which to employ visiting lecturers. We assume that we received financial resources because of the special nature of the course involving community partners. It is rare to receive extra funding because teachers are supposed to organize courses around their own expertise, thereby incurring no extra expenses. Because the multisensory ethnography course was not in the curriculum, which had been settled in the previous semester, it was not included in two of the teachers' work plans. Hence, it was classified as "extra work".

There was always a possibility that there would not be enough participating students because the course was optional. This meant extra stress to market the course more than usual. The planning of the course took a lot of time and effort. There were a lot of details to consider, for example a privacy policy, a data management policy, and students' insurance. There are rarely ready answers about how to manage things when doing something differently. We had to meet regularly and plan the course carefully to avoid various possible complications.

On the sensory ethnography course, we fortunately had all the financial resources we needed but lacked time. This then meant doing unpaid overtime, which is not unprecedented in academia, but this was one reason why the development work was not adopted as a part of the teaching strategy. The publication merits are more valuable than the time invested in pedagogical development, especially when applying for jobs or funding in higher education. We argue that the university environment is contradictory in terms of developing pedagogy. Our loose job descriptions provide ample space to choose how to develop our work. The university encourages the development of teaching, at least in festive speeches, but at the same time, the lack of time and structural conditions encourage us to concentrate on other activities such as writing research plans and publications.

Because adapting connective pedagogy is time consuming for staff [6], it should also be somehow compensated. It emphasizes the importance of the role of the employer and working environment, the material element of teaching practices. Making social practices lasting requires interconnected internal and external rewards for the people making the change [5]. Internal rewards located in the third element of social practices are especially important and closely related to personal motivation and commitment. According to our results in practicing connective pedagogy, the material element 
was the weakest one. We had a lot of extra resources for organizing the course, but these did not come from the university but our own social networks.

\subsection{The Teachers' Competence Element in Practicing Connective Pedagogy}

The connective pedagogy approach challenged us to evaluate our own competences as teachers. We all have pedagogical qualifications in teaching, but the problem-based method makes the work description more complicated than traditional lecturing. We have identified the following diverse competences that, in our experiences from the multisensory ethnography course, are emphasized in the problem-based approach:

- management and organizing competence;

- content expertise and scientific competence;

- supervising group work and learning/facilitator competence;

- social, communicative, and mediating competence;

- reflection and assessment competence;

- technical (digital) competence.

Organizing the course in co-operation with the community partner required a lot of management and organizing. The management required several meetings between teachers and community partners and an effective division of labour. Tasks had to be divided between the teachers and the community partners. Communication between different actors was crucial, emphasizing social and mediating competence. On a traditional lecturing course, there far fewer such tasks, and teachers can focus on the actual content of the teaching.

There were three teachers and visiting lecturers on this course. One of us taught multisensory ethnography, and one of us brought the civil society perspective to the course. The third teacher contributed knowledge about the new ethics law and privacy issues that applied to our research. We asked a teacher from the local university of applied sciences to come to tell us about rural community development. In addition to this, there were two other teachers from the university giving instructions about visual and discourse analysis methods. The course involved so many experts that one might claim that there was a lot of scientific competence. Including a tourism research expert in our team would have been ideal so as to avoid a visiting lecture. On the other hand, the fact that we were moving to an unfamiliar field made the course more exciting and gave us the opportunity to learn something new.

The students did most of their work in groups, which emphasized our teachers' role as facilitators, trying to support and supervise their learning with each other [21]. The situation was at times rather confusing for us, too, because we were not sure, for example, if we instructed too much, enough, or too little. The role of facilitator was challenging because we had to tolerate uncertainty, spontaneous changes in the plans, and be sociable and communicative about it. The course involved a lot of negotiating and communicating with different actors. From the communities of practice perspective, it was important to try to find a "common language" with our partners. This meant that we had to be able to talk about scientific methods and concepts in such a way as not to exclude our community partners from the discussions.

Often, university co-operation in terms of teaching or research with outside communities means that there is a certain part of the project that is open to "outsiders", but most of the science is made invisible to them. We believe that the more open we are with our scientific goals and points of view, the more open the partners will be to respect them. Being a learning community meant that we as teachers also wanted to be open to learn from the community development point of view and from the students. Because the students had no exams on set books or scientific essays to complete, the emphasis in the assessment was on the evaluation of the students' learning and group work processes. Reflective competence is important not only in assessing the students' outcomes but our own motivation and learning from the teaching experience. In a connective curriculum, assessment is seen 
more broadly than in traditional teaching and also involves social, reflective, and dialectic elements [6]. On the sensory ethnography course, we wanted to emphasize verbal and positive feedback, which was given in group discussions, the role of the partners also being important.

In practice, co-operation with a third sector partner entails efforts to build a community of practice with shared goals and commitment [41] emphasizing the role of collaboration, trust, and participation. A dialectic approach and connective pedagogy, however, are also a learning process which will never be complete. After the course, we discussed how we could have increased the connective element in our actions. During the debriefing sessions, we realized that we should have invited our collaborative third sector partners, the organizers of the test days, to share not only their views about the group dynamics but also their experiences. Together, we could have efficiently planned the next phase of coursework and could have created better instructions for the students about the main assignments of interpreting the fieldwork data and designing the marketing material. Instead of one of us acting as a contact person to listen to the wishes and thoughts of the community partners, we should have planned the instructions together. Even if we used a lot of time resources on planning the course and building the co-operation between different actors, the collaboration could have been even more intense than it was.

When living and working in a digitalized world, some technical competence is also required of university teachers, whatever the pedagogical approach they use. Digital learning environments change and develop fast, and most teachers are not able to utilize them as well as possible. On the sensory ethnography course, we used the Moodle platform, which is quite easy to handle, but we were not as familiar with the environment as we should have been. We managed to build the course environment in Moodle, but there were frustrating moments when we wondered about the size of the data we could put there or if the students could receive the needed information from the system.

Adding problem-based learning methodology to connective pedagogy adds more pressure on teachers to tolerate uncertainty. According to Wenger [14], social learning is most effective when the competence and the experience of the learners are not too close to each other. This emphasizes the reflective competence of the teachers but also the attitude of an explorer in developing pedagogy. Teachers are also required to accept that they are also learners among students and partners. Such situations enable teachers to connect with their boundaries. The best learning environment is formed when teachers' experience and competence are in tension, meaning that there is open engagement with real differences as well as common ground [14]. When teachers engage in "boundary crossing" the situation forces them to re-evaluate their own assumptions [15]. A teacher is not an expert imparting knowledge to students, but a fellow traveler whose task is not only to facilitate students but who is also keen to learn more about developing herself. This entails recognition of the incompleteness of one's own expertise and that the competence element of teaching practices should be seen more as a process than a as resource.

Teaching practices are usually quite stable, but there are still constant changes in and between the elements of social practices. The competence element increases, and the working environment is in a state of constant change. According to social practice theory [5], after competence increases the actors are more committed to maintain and develop the social practices they are involved with. We could assume that as teachers the more experience we gained of connective pedagogy and problem-based approaches the more they became a part of our everyday teaching. This means that they become normalized for us, which is a key factor in consolidating any new practices [5]. However, according to our data, the pressure to invest our time in writing academic publications and applications rather than developing teaching may prevent these new practices from becoming a part of our routine way of working in the university. The motivation to develop pedagogical skills depends on how the academic staff perceives the role of teaching as a part of their academic careers and building academic competence. 


\subsection{The Meaning Element is at the Core of Change in Teaching Practices}

The multisensory ethnography course emphasized teachers' social, mediating and management competences. Even if competences can be developed through training and teaching experience, they are still closely related to the teachers' personalities. For example, an introvert person may find it difficult and stressful to make use of such a working method. It is important that teachers can build their identities and everyday work around their own personalities and appreciations [42]. It can be argued that a problem-based approach is not suitable for everyone. For us, it seemed a natural way to act but we are aware that staff members have different kinds of personalities with different strengths and weaknesses. Our weakness was obviously our lack of digital skills, which is related to the fact that we are not so interested in digital technology and systems in a same way as we are interested in connective pedagogy.

The need for change in pedagogical practices usually arises from the teachers' internal experiences and reflections [24], emphasizing the teachers' own motivation in adopting a new teaching method. The same applies to all social practices; the meaning element is what causes people to do things in certain ways [5]. In our case, we were very excited to test the problem-based approach, and the results of this research would have been very different if we had studied teachers compelled to use the method. The meanings we attach to teaching and learning are according to the principles of connective pedagogy and the problem-based approach. Even with no resistance to the new method, we sometimes found it challenging and difficult. Several concurrent courses with this method might have felt too laborious. One reason is that we were doing this for the first time, and we were still in the learning stage, but in connective pedagogy, every project and course is different, and even if the teachers get more experience, they are still always dealing with a new phenomenon or problem to be solved. This emphasizes the importance of the material element and time resources in adopting new teaching methods.

Connective pedagogy challenges the traditional identities of university staff to reevaluate their views about their role in the wider community [6]. In addition to the aspiration to learn and try out new teaching methods, connective pedagogy also requires motivation to participate in the lives of the partner communities and to help them to solve practical real-life problems. The teachers should be keen to change the world and not just study it critically. Becoming a community of practice where teachers, students, and partners learn from each other requires engagement and the sense of belonging $[16,17]$.

After the closing seminar it felt that we had really accomplished something. I don't think that the feeling comes from the students' learning outcomes but from the fact that we have achieved something concrete. Students produced advertising material for the project, and they might google these villages and their tourist attractions after a few years and think "Wow, I was involved with this process." This is rare experience in the university environment, to see our handprint in some concrete environment. It feels empowering. (Personal Notes)

We found it inspiring and empowering on the multisensory ethnography course that we and the students could make an impact on the process of developing village tourism in the two villages and even on a larger scale on rural tourism at the regional level.

Professional identity is an individual's cultural and social self-formation process in the context of work [43]. The academic professional identity is multiple and often also fragmented because of the various local and international, research and teaching communities to which the teachers are connected [44]. There are also differences as to the role played by the communities outside the scientific field in teachers' professional identity formation. There may be some contradictions between the principles of connective pedagogy and traditional university teaching, but at the individual and social level, it is also a question of identity. If a teacher perceives herself as a strictly theoretical expert not interested in getting involved in practical questions, the connective approach may not be the right method. 
The question of professional identity is not just about whether the teacher wants to focus more on research or teaching. In fact, a researcher's attitude helps teachers accept their lack of knowledge and expertise when starting any new connective project. When a group of people-teachers, students, and partners-study some practical problem by combining theoretical and practical knowledge, the situation is very similar to that in many empirical research projects.

It feels a little bit like being on a voyage of exploration. I feel nervous and excited at the same time. The people from the village organization are coming to our lectures and I think they expect to learn something new from us. We should remember to tell the visiting lecturers that they should not use too academic language. There is also a risk that the people from the village organization don't think that our points are relevant for their purposes. It is good that we have to think about the way we construct these teaching sessions, but it feels also a little bit stressful to try to think so many things at the same time. (Personal Notes)

Both, the students' and the teachers' research skills are practiced in connective pedagogy, thus it should not be seen as opposed to the "actual" researcher's work. Brew [45] talks about the traditional model of the relationship of teaching and research, which shows that in the university there is a division in how knowledge is seen and defined depending on the context. In research, it is something that is generated, but in teaching, it is something that is just transmitted to the students. In connective pedagogy, the set-up is more complicated and nuanced [6]. Lack of motivation on the part of university staff to develop pedagogical competence reflects the traditional division; researchers do not feel that teaching practices increase their opportunities for promotion in their research careers. Connective pedagogy challenges this traditional division of knowledge and competence by integrating teaching with research.

\section{Discussion}

The objective of this article was to reveal some obstacles and potentialities that can be taken into consideration in developing connective pedagogy with problem-based learning in higher education. By analysing our own experiences through social practice theory, we sought answers to why pedagogical reforms can be challenging from the teachers' point of view and what kind of support should be available when promoting pedagogical innovations at policy level.

The sustainable change of social practices, in our case the connective pedagogy becoming a long-lasting part of our teaching, requires that all the elements of social practices should be in accordance with the new approach. Material and competence elements should be available to support the ambition of the teachers to organize courses according to the principles of Connected Curriculum. The material element includes university policy, structures, and resources that construct the boundaries of developing teaching as a part of everyday work at the university. The motivation and the professional identity of the teachers are at the centre, where the commitment to connective pedagogy arises. The competences of the teachers are related to other elements reflecting the personal, social, and cultural appreciations of the teachers but are also strongly affected by university policy and the resources available.

The university can influence teachers' motivation by encouraging them and giving them opportunities to develop their professional teaching skills. However, teachers have differing personalities, and it should be understood that connective pedagogy does not appeal to everyone. It also requires continuous learning and tolerance of uncertainty. We contend that, to be able to build connective pedagogy, we as teachers need the support to be able to reflect our experiences and feelings during the process. The members of the work community and a non-judgmental atmosphere as well as time as a key resource are important in enabling the professional development of teachers.

The main obstacle to practicing connective pedagogy or adopting any other new pedagogy model is the lack of time. When time is not allocated for new kinds of teaching methods, teachers need to work overtime, and they begin to resist any changes or developments. Even planning a new way of teaching requires more time than a traditional lecture frame. We argue that developing teaching 
enhancing students' learning, experience and employability should become a part of the teachers' routine, not something that means extra working hours. It should also be considered in teachers' work plans. We hope that teachers would be motivated and engaged in the practice of connective pedagogy. It should not be something merely recommended for consideration in the curriculum work. Instead, teachers should receive training in it and be incentivized to use new teaching methods and to develop partnerships with the local communities.

Hence, Wenger [14] suggests that brokers, people who act between communities and universities creating connections, could help to introduce one element from one practice into another. Brokers could assist teachers who do not have time resources, enough different competences, or who are possibly just not interested and motivated to build partnerships. In the British universities, this has been solved by creating separate public engagement units. Northmore and Hart [46] argue that universities need infrastructure for sustainable partnerships because without these partnerships are too dependent on particular leaders or funders. The staff's purpose is to create and maintain good relations to the local and global partners $[16,46]$.

Also, our reflections showed us that developing teacher's pedagogical competence was not as highly appreciated as publishing articles. This conflicts with the fact that the university's first mission is to teach. However, all university teachers, lecturers, and professors are supposed to constantly engage in research and publishing while teaching. Their competence to teach is measured through these, which has nothing to do with the teaching philosophy. Hence, connective pedagogy challenges the traditional way of thinking in academia. The university should pay more attention to the teaching atmosphere and reward teachers for good teaching practices and for participating in training.

We found the problem-based approach an effective method for building connective pedagogy but there are also some contradictions between the method and the principles of communities of practice in cultural studies. The concept of solving problems refers to problems that are technical and can be solved by certain actions. In social learning processes that deal with cultural and social phenomena the "problems" are usually more or less permanent and cannot be "solved". Connective pedagogy can recognize challenges, promote positive tasks, and help to bring people together to make the world a slightly better place to be, but not to solve these "problems". There is a need to develop concepts that shape the problem-based approach to better serve the nature of social learning in the cultural field.

The first limitation of our research is that we focused solely on teachers' perspectives and experiences. However, in developing connective pedagogy, it would also be important to study the partners' perspectives on the challenges they encountered in working with us. We do not know, for example, how they felt about the changing roles in the process. We will address students' experiences in another paper because we also need to consider the working life skills they learned or did not learn. As the ethnographic method is a subjective tool, it emphasizes the role of ethics in reflecting and revealing the process through which the interpretations are constructed. The connective approach is based on building a dialogue between different parties which makes the process even more challenging, and we as researchers have to be also able to question our own interpretations.

Our study resulted in new perspectives on the connective and problem-based research fields by applying social practice theory through the ethnographic method. Social practice theory enabled us to analyse the process of teaching from diverse angles and without simplifying the complicated process of change. The ethnographic method is valuable in studying people's everyday lives, experiences and the meanings they attach to their lives, but there are limitations to the generalization of the research results. Every actor or teacher experiences their work subjectively and in a different way. This is also why we deem it important to bring the teachers' experimental perspective into discussions on developing higher education pedagogy: teaching in teams and co-teaching bring different competences and perspectives to the learning process.

This process not only taught us something about connective pedagogy and the problem-based approach, but also how we can see our everyday teaching (or any other work) as a research process. The scientific perspective helps us to reflect our daily and taken-for-granted activities and to make 
research and development a part of everyday work. Teaching need not be an obstacle to doing research but an integral part of it. According to our results, if the university would encourage teachers to include more research elements in their teaching, the motivation to invest in developing pedagogy would also increase. In developing teaching, it is also important to consider various ethical aspects. In this article we concentrated on the teachers' perspective, but all the reforms should also be reflected from the students' point of view, how they support their learning and the growth of professional identity.

In this age of digital transformation, we should not forget the significance of face-to-face meetings and social learning. It is not only a question of acquiring working life skills but also a part of students' wellbeing and of building of their professional identities. The lack of connective practices is a challenge not only for university pedagogy, but also for hectic working life in general. The crucial question is how to build communities of practice with "the sense of joint enterprise" [14] or engagement and belonging $[17,46]$. Universities could be examples of such joint engagements that pave the way for overall wellbeing and better working life. In future research, the ethnographic method could be an effective instrument to study the social process of learning and building communities of practice. There is a lot of evidence about the importance of communities and social networks, but how the subjectivity of different actors and the dialogue between them are constructed and maintained in the process remains unknown. Cultural studies and methods have a lot to offer in this field of education science.

Author Contributions: E.K.-K.: methodology and ethical considerations, S.V.: teaching philosophy, K.K.: introduction, social practice theory and results. K.K. and S.V.: discussion.

Funding: This research received no external funding and it was conducted as part of the development of the degree programme Cultures, Communities and Change at the University of Jyväskylä. Eerika Koskinen-Koivisto's work is funded by Emil Aaltonen Foundation.

Conflicts of Interest: The authors declare no conflict of interest.

\section{References}

1. Jääskelä, P.; Nykänen, S.; Tynjälä, P. Models for the Development of Generic Skills in Finnish Higher Education. J. Furth. High. Educ. 2018, 42, 130-142. [CrossRef]

2. Savin-Baden, M.; Major, C.H. Foundations of Problem-Based Learning; Society for Research into Higher Education \& Open University Press: Maidenhead, UK, 2004.

3. Pekkarinen, V.; Hirsto, L. University Lecturers' Experiences of and Reflections on the Development of Their Pedagogical Competency. Scand. J. Educ. Res. 2017, 61, 735-753. [CrossRef]

4. Tynjälä, P.; Välimaa, J.; Boulton-Lewis, G. Pedagogical Perspectives on the Relationships between Higher Education and Working Life: Collaborations, Confrontations and Challenges; Elsevier: Oxford, UK, 2006.

5. Shove, E.; Pantzar, M.W.; Watson, M. The Dynamics of Social Practice. Everyday Life and How It Changes; Sage: London, UK, 2012.

6. Fung, D. A Connected Curriculum for Higher Education; UCL Press: London, UK, 2017.

7. Guile, D.; Griffiths, T. Pedagogy in work-based context. In Understanding Pedagogy and Its Impacts on Learning; Mortimore, P., Ed.; Paul Chapman Publishing: London, UK, 1999; pp. 155-174.

8. Guile, D.; Griffiths, T. A connective model of learning: The implications for work process knowledge. Eur. Educ. Res. J. 2003, 2, 56-73.

9. Mulligan, M.; Nadarajah, Y. Working on the sustainability of local communities with a "community-engaged" research methodology. Local Environ. 2008, 13, 81-94. [CrossRef]

10. Tynjälä, P.; Stenström, M.-L.; Saarnivaara, M. Transitions and Transformations in Learning and Education; Springer: Dordrecht, The Netherlands, 2012.

11. Tynjälä, P. Asiantuntijuuden kehittämisen pedagogiikka. In Luovuus, Oppiminen ja Asiantuntijuus; Collin, K., Paloniemi, S., Rasku-Puttonen, H., Tynjälä, P., Eds.; WSOYpro: Helsinki, Finland, 2010; pp. 79-95.

12. Corbett, J. Supporting Inclusive Education; Routledge: London, UK, 2001.

13. Carnell, B.; Fung, D. Developing the Higher Education Curriculum. Research-Based Education in Practice; UCL Press: London, UK, 2017.

14. Wenger, E. Communities of Practice and Social Learning Systems. Organization 2000, 7, 225-246. [CrossRef] 
15. Wenger, E.; McDermott, R.; Snyder, W.M. Cultivating Communities of Practice; Harvard Business School Press: Boston, MA, USA, 2002.

16. Hart, A.; Northmore, S. Auditing and Evaluating University-Community Engagement: Lessons from a UK Study. High. Educ. Q. 2011, 65, 34-58. [CrossRef]

17. Hart, A.; Wolff, D. Developing local 'communities of practice' through local community-university partnerships. Plan. Pract. Res. 2006, 21, 121-138. [CrossRef]

18. Collin, K.; Tynjälä, P. Integrating theory and practice? Employees' and students' experiences of learning at work. J. Workplace Learn. 2003, 15, 338-344. [CrossRef]

19. Andersen, S.A.; Heilesen, S.B. The problem-oriented project work (PPL) alternative in self-directed higher education. Innov. High. Educ. Teach. Learn. 2015, 3, 23-41.

20. Hmelo-Silver, C. Problem-Based Learning: What and How Do Students Learn? Educ. Psychol. Rev. 2004, 16, 235-266. [CrossRef]

21. Savin-Baden, M. Facilitating Problem-Based Learning: Illuminating Perspectives; Society for Research into Higher Education \& Open University Press: Maidenhead, UK, 2003.

22. Boud, D. Problem-based learning in perspective. In Problem-Based Learning in Education for the Professionals; Boud, D., Ed.; HERDSA: Brisbane, Australia, 1985; pp. 13-18.

23. Tynjälä, P.; Virtanen, A.; Klemola, U.; Kostiainen, E.; Rasku-Puttonen, H. Developing social competence and other generic skills in teacher education: Applying the model of integrative pedagogy. Eur. J. Teach. Educ. 2016, 36, 368-387. [CrossRef]

24. Mälkki, K.; Lindblom-Ylänne, S. From reflection to action? Barriers and bridges between higher education teachers' thoughts and actions. Stud. High. Educ. 2012, 37, 33-50. [CrossRef]

25. Shove, E.; Watson, M.; Hand, M.; Ingram, J. The Design of Everyday Life; Berg: Oxford, UK, 2007.

26. De Krom, M.P.M.M. Governing animal-human relations in farming practices: A study of group housing of sows in the EU. Sociol. Rural. 2015, 55, 417-437. [CrossRef]

27. Huttunen, S.; Oosterveer, P. Transition to sustainable fertilisation in agriculture, a practices approach. Sociol. Rural. 2016, 57, 191-210. [CrossRef]

28. Soini, K.; Huttunen, S. Cultivating cultural sustainability in farming practices. In Cultural Sustainability and the Nature-Culture Interface. Livelihoods, Policies and Methodologies. Routledge Studies in Culture and Sustainable Development; Birkeland, I., Burton, R., Parra, C., Siivonen, K., Eds.; Routledge: London, UK, 2018; pp. $35-48$.

29. Shove, E. Putting practice into policy: Reconfiguring questions of consumption and climate change. Contemp. Soc. Sci. 2014, 9, 415-429. [CrossRef]

30. Campbell, H.; Rosin, C.; Hunt, L. The social practice of sustainable agriculture under audit discipline: Initial insights from the AGROS project in New Zealand. J. Rural Stud. 2012, 28, 129-141. [CrossRef]

31. Giddens, A. The Constitution of Society: Outline of the Theory of Structuration; Polity Press: Cambridge, UK, 1984.

32. Bourdieu, P. The Logic of Practice; Polity Press: Cambridge, UK, 1990.

33. Schatzki, T. Practices and actions: A Wittgensteinian critique of Bourdieu and Giddens. Philos. Soc. Sci. 1997, 27, 283-308. [CrossRef]

34. Warde, A. Consumption and theories of practice. J. Consum. Cult. 2005, 5, 131-153. [CrossRef]

35. Maller, C.J. Understanding health through social practices: Performance and materiality in everyday life. Sociol. Health Illn. 2015, 37, 52-66. [CrossRef]

36. Reeves, S.; Kuper, A.; Hodges, B.D. Qualitative research methodologies: Ethnography. BMJ 2008, 337, a1020. [CrossRef]

37. Murchison, J.M. Ethnography Essentials: Designing, Conducting, and Presenting Your Research, 1st ed.; Jossey-Bass: San Francisco, CA, USA, 2010.

38. Hämeenaho, P.; Koskinen-Koivisto, E. Etnografian ulottuvuudet ja mahdollisuudet. In Moniulotteinen etnografia; Hämeenaho, P., Koskinen-Koivisto, E., Eds.; Ethnos ry: Helsinki, Finland, 2014; pp. 7-31.

39. Pink, S. Doing Sensory Ethnography; SAGE: London, UK, 2009.

40. Sparkes, A.C. Ethnography and the senses: Challenges and possibilities. Qual. Res. Sport Exerc. 2009, 1, 21-35. [CrossRef]

41. Seaman, M. Birds of a feather? Communities of practice and knowledge communities. Curric. Teach. Dialogue 2008, 10, 269-279.

42. Mikelsone, I.; Odina, I.; Gridule, L. Conceptualizing the understanding of professional identity in teacher's career. Eur. Sci. J. 2014, 1. 
43. Haamer, A.; Lepp, L.; Reva, E. The dynamics of professional identity of university teachers: Reflecting on the ideal university teacher. Stud. Learn. Soc. 2012, 2, 110-120. [CrossRef]

44. Kreber, C. Academics' teacher identities, authenticity and pedagogy. Stud. High. Educ. 2010, 35, 171-184. [CrossRef]

45. Brew, A. Research and Teaching: Beyond the Divide; Palgrave Macmillan: London, UK, 2006.

46. Northmore, S.; Hart, A. Sustaining community-university partnerships. Gatew. Int. J. Community Res. Engagem. 2011, 4, 1-11. [CrossRef]

(C) 2019 by the authors. Licensee MDPI, Basel, Switzerland. This article is an open access article distributed under the terms and conditions of the Creative Commons Attribution (CC BY) license (http://creativecommons.org/licenses/by/4.0/). 